\title{
Eleutheroside B1 mediates its anti-influenza activity through POLR2A and N-glycosylation
}

\author{
WEN YAN ${ }^{1,2}$, CHUNGE ZHENG $^{1}$, JIAYANG HE ${ }^{1}$, WENJIE ZHANG ${ }^{3}$, XIN-AN HUANG ${ }^{1}$, \\ XIONG $\mathrm{LI}^{4}$, YUTAO WANG ${ }^{3}$ and XINHUA WANG ${ }^{3}$ \\ ${ }^{1}$ Institute of Tropical Medicine, Guangzhou University of Chinese Medicine, Guangzhou, Guangdong 510405, P.R. China; \\ ${ }^{2}$ Centre d'Immunologie de Marseille-Luminy, CIML, Aix-Marseille Université, CNRS, INSERM, 1-3009 Marseille, France; \\ ${ }^{3}$ State Key Laboratory of Respiratory Disease, National Clinical Research Center for Respiratory Disease, \\ Guangzhou Institute of Respiratory Health, First Affiliated Hospital of Guangzhou Medical University, Guangzhou, \\ Guangdong 510120; ${ }^{4}$ Department of Integrated Chinese Medicine Immunization and Section Rheumatology Research, \\ The Second Affiliated Hospital, Guangzhou University of Chinese Medicine, Guangzhou, Guangdong 510006, P.R. China
}

Received April 16, 2018; Accepted September 4, 2018

DOI: $10.3892 / \mathrm{ijmm} .2018 .3863$

\begin{abstract}
Influenza viruses represent a serious threat to human health. Although our research group has previously demonstrated the antiviral and anti-inflammatory activities of eleutheroside B1, a detailed explanation of the mechanism by which it is effective against the influenza virus remains to be elucidated. In the present study, the transcriptomic responses of influenza A virus-infected lung epithelial cells (A549) treated with eleutheroside B1 were investigated using high-throughput RNA sequencing, and potential targets were identified using a molecular docking technique, reverse transcription-quantitative polymerase chain reaction (RT-qPCR) assay, and DNA methylation analysis. The transcriptomic data revealed that there are 1,871 differentially expressed genes (DEGs) between the cells infected with the influenza virus strain variant PR8, and the cells infected with PR8 and treated with eleutheroside B1. Among the DEGs, RNA polymerase II subunit A (POLR2A; encoding the largest subunit of RNA polymerase II) and mannosidase $\alpha$ class II member 1 (MAN2A1) were selected from the molecular docking analysis with eleutheroside B1. The docking score of Drosophila melanogaster MAN2A1 (3BVT) was 11.3029, whereas that of POLR2A was 9.0133. The RT-qPCR results demonstrated that
\end{abstract}

Correspondence to: Dr Yutao Wang or Professor Xinhua Wang, State Key Laboratory of Respiratory Disease, National Clinical Research Center for Respiratory Disease, Guangzhou Institute of Respiratory Health, First Affiliated Hospital of Guangzhou Medical University, Guangzhou, 195 Dongfeng Xi Road, Guangzhou, Guangdong 510120, P.R. China

E-mail: wang-yu-tao2008@163.com

E-mail: xinhuaw@gzhmu.edu.cn

Key words: eleutheroside B1, influenza virus, RNA sequencing, RNA polymerase II subunit A the expression levels of host genes (MAN2A2, POLR2A) and viral genes (PA, PB1, PB2, HA) were downregulated following eleutheroside B1 treatment. Bisulfite-sequencing PCR was performed to investigate whether eleutheroside B1 was able to modify the DNA methylation of POLR2A, and the results suggested that the average proportion of methylated $\mathrm{CpGs}$ (-222-72 bp) increased significantly following treatment with eleutheroside B1. Taken together, these findings suggested that eleutheroside B1 may affect $\mathrm{N}$-glycan biosynthesis, the chemokine signaling pathway, cytokine-cytokine receptor interaction and, in particular, may target the POLR2A to inhibit the production of influenza virus genes.

\section{Introduction}

Influenza A viruses cause worldwide outbreaks of influenza and seasonal pandemics, and pose serious risks to public health (1). Influenza A viruses belong to the Orthomyxoviridae family, with a negative single-stranded, segmented RNA genome, and have been categorized into different subtypes on the basis of their hemagglutinin and neuraminidase antigens (2). Their negative-sense RNA genomes have no proof-reading mechanism during replication, so they are extremely error-prone, giving rise to a high mutation rate (3). Therefore, it is a lengthy process to update the matched vaccine for these quickly modifying viruses, and it is necessary to continually develop novel effective antiviral drugs against influenza viruses in order to prepare for the continual seasonal outbreaks.

Currently available anti-influenza virus drugs target the viral life cycle, including amantadine, rimantadine, oseltamivir, zanamivir and peramivir. However, prolonged treatment and the resulting immuno-compromised status of patients lead to increases in drug-resistant mutations among influenza viruses worldwide (4). Previous studies have indicated that the influenza strains $\mathrm{H} 3 \mathrm{~N} 2$ and pdmH1N1 are resistant to adamantanes (5), and the latest outbreak of the H7N9 virus is also resistant to oseltamivir (6). On the other hand, novel antiviral drugs derived from traditional Chinese medicine 
(TCM) do not tend to lead to the development of drug resistance among the viruses so easily. Therefore, numerous studies have focused on developing anti-influenza drugs using natural resources, such as traditional medicines, which offer hopeful new prospects for influenza management $(1,7)$.

Coumarin is a fragrant organic chemical compound of the benzopyrone chemical class that is a natural substance found in many plant species, which exhibits a variety of potent pharmacological activities, including antioxidant, antibacterial, anti-inflammatory, antitumor and antiviral activities (8-13). Previous studies by our research group have demonstrated that eleutheroside B1, a coumarin compound, has a wide spectrum of anti-human influenza virus efficacy, with an $\mathrm{IC}_{50}$ value (i.e., the concentration which leads to half-maximal inhibition) of 64-125 $\mu \mathrm{g} / \mathrm{ml}$ in vitro, and it inhibited the mRNA expression of several chemokine genes and the influenza nucleoprotein (NP) gene, while exhibiting low cytotoxicity (14).

Over the past few decades, computational chemistry, molecular biology, pharmacognosy and biotechnology have become major scientific areas for the research of natural products. Some modern technologies, including RNA sequencing and molecular docking, have also been used to identify novel molecules for the effective treatment of diseases, and to investigate the underlying mechanisms of action and the specific targets, as well as DNA, RNA, protein and enzyme interactions, associated with natural products (15). RNA sequencing is a genome-wide analytical technology that has been used to analyze the transcriptome of the host response to human or avian influenza virus infection $(16,17)$. A previous study has also used this technology to provide a comprehensive analysis of the pharmacological effects of natural products (18). The molecular docking approach has become an increasingly important tool in pharmaceutical research, and can be used to model the interaction between a small molecule and a protein at the atomic level, which enables the identification of potential drug targets, as well as the ability to characterize the behavior of small molecules in the binding site of target proteins (19). In the present study, the pathway profiles of influenza A virus-infected lung epithelial (A549) cells following eleutheroside B1 treatment were assessed, which has enabled us to gain a comprehensive understanding of the mechanism of eleutheroside B1 activity against influenza A viral infection. From the RNA sequencing results, it was determined that eleutheroside B1 may exert its pharmacological effects on multiple targets, including the immune system, the glycan biosynthesis and metabolism pathways, signaling molecules and their interactions, transcriptional regulation of the chemokine signaling pathway, various types of $\mathrm{N}$-glycan biosynthesis, and cytokine-cytokine receptor interaction. A molecular docking approach was subsequently used to investigate the potential target receptor proteins for eleutheroside B1. Finally, a variety of molecular biology techniques, including reverse transcription-quantitative polymerase chain reaction (RT-qPCR) assay, bisulfite treatment and DNA methylation analyses, were used to evaluate the results from the RNA sequencing and molecular docking experiments.

\section{Materials and methods}

Compounds, cells and viruses, and software. Eleutheroside B1 was purified from Sarcandra glabra extract (Si Chuan, China)
Table I. Primer sequences.

\begin{tabular}{lll}
\hline Gene & Primer & \multicolumn{1}{c}{ Sequence (5'-3') } \\
\hline PA & $\begin{array}{l}\text { Forward } \\
\text { Reverse }\end{array}$ & $\begin{array}{l}\text { ACACTACAGGGGCTGAGAAA } \\
\text { TGAACGAGAAAATGTGGATG }\end{array}$ \\
PB1 & Forward & AGTTTTGGTGTGTCTGGGA \\
& Reverse & TTCGGGTTTGTATTTGTGG \\
PB2 & Forward & ACCCAGATGAAGGCACAG \\
& Reverse & TAGAGTCCCGTTTCGTTTC \\
POLR2A & Forward & GATGAACTGAAGCGAATGTCT \\
& Reverse & GTCGTCTCTGGGTATTTGATG \\
HA & Forward & TGAACAGGGAAAAGGTAGATG \\
& Reverse & CAGGGAGACCAAAAGCAC \\
MAN2A2 & Forward & GCCCTCATTTTCTGTTTATTG \\
& Reverse & CTGCCCTATTTACCCATCAC \\
GAPDH & Forward & GCTGAGTATGTTGTGGAGTC \\
& Reverse & GCAGAAGGAGCAGAGATGA
\end{tabular}

POLR2A, RNA polymerase II subunit A; HA, hemagglutinin; MAN2A1, mannosidase $\alpha$ class II member 1 .

and characterized by high-resolution mass spectrometry and ${ }^{1} \mathrm{H}$ and ${ }^{13} \mathrm{C}$ nuclear magnetic resonance spectroscopy, as described previously (13). The purity of the compound exceeded $98 \%$, according to analysis by ultra-performance liquid chromatography/time-of-flight mass spectrometry. Eleutheroside B1 was dissolved in dimethyl sulfoxide (Sigma-Aldrich; Merck $\mathrm{KGaA}$, Darmstadt, Germany) as a stock solution of $50 \mathrm{mg} / \mathrm{ml}$, and stored at $-20^{\circ} \mathrm{C}$ until use. A549 cells were purchased from the American Tissue Culture Collection (ATCC; Manassas, VA, USA). The cells were grown in Dulbecco's modified Eagle's medium with $10 \%$ fetal bovine serum under standard conditions at $37^{\circ} \mathrm{C}$ in $5 \% \mathrm{CO}_{2}$ humidified air. The influenza virus strain A/PR/8/34 (H1N1) was also purchased from ATCC. The influenza viruses were propagated in the allantoic cavities of chicken eggs. ORCID iD of ChemDraw Ultra 8.0 and SYBYL-X2.1.1 software was used in this study (no. 0000-0003-1628-7416), kindly provided by Dr Xin-An Huang (Tropical Medicine Institute, Guangzhou University of Chinese Medicine, Guangzhou, China).

Cell culture, virus infection and sample preparation. The A549 cells were grown in a monolayer up to $80 \%$ confluency and detached from the flask using $10 \mathrm{mM}$ EDTA (pH 7.4) and $0.25 \%$ trypsin. The cells were harvested, and $6 \times 10^{5}$ A549 cells were seeded in 6-well tissue culture plates. On the following day, the cells were washed twice with PBS and infected with A/PR/8/34 [H1N1; 0.1 multiplicity of infection (MOI)] using serum-free medium for $2 \mathrm{~h}$ at $37^{\circ} \mathrm{C}$. The inoculum was removed, and the cells were treated with or without eleutheroside B1 at a concentration of $100 \mu \mathrm{g} / \mathrm{ml}$ (14). At $24 \mathrm{~h}$ post-infection, the cells were lysed in TRIzol reagent (Thermo Fisher Scientific, Inc., Waltham, MA, USA) and stored at $-80^{\circ} \mathrm{C}$.

RNA isolation, cDNA library construction and sequencing. Total RNA extracts from each sample were obtained with 
Table II. RNA-seq overview: Reads mapping quality summary.

\begin{tabular}{lcccccccc}
\hline $\begin{array}{l}\text { Sample } \\
\text { name }\end{array}$ & $\begin{array}{c}\text { Total } \\
\text { reads }\end{array}$ & $\begin{array}{c}\text { Total } \\
\text { bases }\end{array}$ & $\begin{array}{c}\text { Mapped } \\
\text { reads }\end{array}$ & $\begin{array}{c}\text { Mapped } \\
\text { rate (\%) }\end{array}$ & $\begin{array}{c}\text { Proper } \\
\text { paired mapped }\end{array}$ & Singletons & $\begin{array}{c}\text { MAPQ } \geq 5 \\
\text { rate }(\%)\end{array}$ & $\begin{array}{c}\text { Discordantly } \\
\text { mapped }\end{array}$ \\
\hline A549 & 34753376 & $5.21 \mathrm{E}+09$ & 33748010 & 97.11 & 33748010 & 0 & 95.26 & 0 \\
PR8 & 33971006 & $5.1 \mathrm{E}+09$ & 32589740 & 95.93 & 32589740 & 0 & 94.10 & 0 \\
PR8+eleu & 34797038 & $5.22 \mathrm{E}+09$ & 33215018 & 95.45 & 33215018 & 0 & 93.40 & 0 \\
\hline
\end{tabular}

TRIzol reagent, according to the manufacturer's instructions (Thermo Fisher Scientific, Inc.). The total RNA quality was analyzed using agarose electrophoresis (1\% gels). The $\mathrm{A}_{260} / \mathrm{A}_{280}$ ratio was determined using a NanoDrop spectrophotometer (NanoDrop Technologies; Thermo Fisher Scientific, Inc.). RNA integrity was assessed by Agilent 2100 TapeStation analysis (Agilent Technologies, Santa Clara, CA, USA). An $\mathrm{A}_{260} / \mathrm{A}_{280}$ ratio between 1.8 and 2.0 and an RNA integrity number $>7$ were considered acceptable parameters for RNA integrity. RNA sequencing was performed on an Illumina X-ten RNA-Seq sequence production system (Illumina, Inc., San Diego, CA, USA).

Pathway analysis of differentially expressed genes (DEGs). In order to obtain a list of DEGs, Gene Ontology (GO) and pathway enrichment analyses were performed. In addition, GO terms, Interpro (protein sequence analysis and classification) terms, and Kyoto Encyclopedia of Genes and Genomes (KEGG) pathways that were significantly enriched on our list of genes with altered expression $(\mathrm{P}<0.05)$ were identified. Additionally, the integrated pathways with statistical values were computed from our list of DEGs using a reactome pathway analysis (http://www.reactome.org/). For over-representation analysis, the number of altered genes associated with a pathway was compared between the treatment and control groups. To determine pathway perturbation, the significance of a particular gene to a pathway was considered in determining the overall impact on the pathway by examining all annotated functions/interactions of the gene.

Targeting and molecular optimization. Two-dimensional $[2 \mathrm{D}(\mathrm{a})]$ and three-dimensional $[3 \mathrm{D}(\mathrm{b})]$ structural information of the compound were obtained from the National Centre for Biotechnology Information (NCBI; (https://pubchem. ncbi.nlm.nih.gov/compound/12302276\#section=Top), and these were saved as mol.2 files. The 3D-formatted molecule was imported into the Pharmaceutical Target Seeker (PTS; http://www.rcdd.org.cn/PTS/result), and a search was conducted. Molecular modeling was conducted with the SYBYL program package (20). Eleutheroside B1 was used as the template. Its conformation was searched and identified by energy minimization using the MMFF94 force field with the Powell conjugate gradient minimization algorithm, and a convergence criterion of $0.005 \mathrm{kcal} /(\mathrm{mol} \bullet \AA)$. The MMFF94 charge was used to calculate partial atomic charges. The parameters were set as defaults.

Protein preparation and docking. Through the PTS, select proteins were identified that were potentially matched with eleutheroside B1. Given our goal of attempting to find a potential target of eleutheroside B1 that would be effective against the influenza virus, and considering our previous results, Golgi mannosidase $\alpha$ class II member 1 (MAN2A1) and RNA polymerase II subunit A (POLR2A) were selected as candidate targets. The four-letter PDB code (3BVT) of Drosophila melanogaster MAN2A1 (with resolution at $1.3 \AA$ ) and the PDB code $(3 \mathrm{D} 9 \mathrm{~N})$ of POLR2A (with resolution at $1.60 \AA$ ) were retrieved from the Protein Data Bank (PDB; http://www. pdb.org/pdb/home/home.do). Structural optimization of the protein was conducted using SYBYL software. The crystal structure of D. melaogaster MAN2A1 was subjected to geometry optimization using the Swiss PDB viewer v4.1.0 program. The compound structure of eleutheroside B1 was prepared for docking using ChemDraw Ultra 8.0 and SYBYL-X2.1.1 software. The execution of molecular docking analysis and visualization were conducted using Surflex-Dock software. The removal of solvent molecules, hydrogen addition, and the AMBER7 FF99 charges calculation were performed. Furthermore, all default parameters were used for docking simulations by SYBYL Vina analysis.

$R T$ - $q P C R$ assay. A549 cells were seeded in 6-well plates at $37^{\circ} \mathrm{C}$ in an atmosphere of $5 \% \mathrm{CO}_{2}$, then infected with influenza virus (strain $\mathrm{A} / \mathrm{PR} / 8 / 34 ; 0.1 \mathrm{MOI}$ ) and subsequently treated with eleutheroside $\mathrm{B} 1$ at a diluted concentration. At $24 \mathrm{~h}$ post-infection, the cells were collected for mRNA expression analysis of the host genes (MAN2A2, POLR2A) and the viral genes [polymerase acid (PA), polymerase basic (PB) 1 and 2 and hemagglutinin (HA)] by RT-qPCR. Total RNA was extracted using TRIzol reagent (Invitrogen; Thermo Fisher Scientific, Inc.). Total RNA $(1 \mu \mathrm{g})$ was reverse transcribed into cDNA using the Prime-Script RT-PCR kit (Takara Biotechnology Co., Ltd., Dalian, China) at $37^{\circ} \mathrm{C}$ for $15 \mathrm{~min}$, $85^{\circ} \mathrm{C}$ for $5 \mathrm{sec}$. The samples were amplified in SYBR Green qPCR buffer (ABP Biosciences, Jiemei long biological Co., Ltd., Wuhan, China). qPCR was performed using an ABI7500 Real-time PCR System (Applied Biosystems; Thermo Fisher Scientific, Inc.) with the following thermocycling conditions: $95^{\circ} \mathrm{C}$ for $3 \mathrm{~min}$, followed by 40 cycles of $95^{\circ} \mathrm{C}$ for $5 \mathrm{sec}$ and $60^{\circ} \mathrm{C}$ for $30 \mathrm{sec}(16)$. Relative gene (PA, PB1, PB2, HA, POLR2A, MAN2A2 and GAPDH) expression levels were calculated using the $2^{-\Delta \Delta C q}$ method (21). Primer sequences are listed in Table I.

CpG island (CGI) prediction. A Hidden Markov Model (HMM)-based CGI prediction for the MAN2A1 and POLR2A gene loci was obtained from the browser (http://www.urogene. org/cgi-bin/methprimer/methprimer.cgi) (22). 
Table III. Significantly enriched GO terms in response to eleutheroside B1.

GO description

Heterocycle biosynthetic process P-value Number of genes

Aromatic compound biosynthetic process

0.001378

6

Organic cyclic compound biosynthetic process

0.001468

Oxidoreductase activity, acting on the $\mathrm{CH}-\mathrm{NH}$ group of donors

0.001584

DNA ligase activity

0.001615

DNA ligation

0.002303

0.002306

DNA ligase (ATP) activity

0.002306

Binding

0.002306

0.002597

Molecular function

0.002715

Intra-Golgi vesicle-mediated transport

0.003632

Establishment of protein localization to Golgi

0.003993

Protein targeting to Golgi

0.003993

Retrograde transport, vesicle recycling within Golgi

0.003993

Protein localization to Golgi apparatus

0.003993

Double-stranded RNA-specific ribonuclease activity

0.004917

Ribonuclease III activity

0.004917

Methylenetetrahydrofolate dehydrogenase (NADP+) activity

0.004917

Negative regulation of transcription, DNA-templated

0.005146

Negative regulation of gene expression

Negative regulation of nucleic acid-templated transcription

0.005146

0.006515

Negative regulation of RNA metabolic process

0.006515

Negative regulation of RNA biosynthetic process

0.006515

0.006757

Nucleobase-containing compound biosynthetic process

0.007534

0.00998

0.00998

Endoribonuclease activity

NADP biosynthetic process

0.010598

0.010598

$\mathrm{NAD}+$ kinase activity

Formate-tetrahydrofolate ligase activity

Regulation of neurotransmitter levels

0.010598

Argininosuccinate synthase activity

Methylenetetrahydrofolate reductase $(\mathrm{NAD}(\mathrm{P}) \mathrm{H})$ activity

0.011107

0.011107

Gamma-tubulin binding

0.011107

0.011107

Pteridine-containing compound biosynthetic process

0.011677

Folic acid-containing compound biosynthetic process

0.011677

Folic acid-containing compound metabolic process

0.011677

DNA topoisomerase type I activity

0.015169

Ligase activity, forming carbon-nitrogen bonds

0.015411

Regulation of Ras protein signal transduction

0.016281

Ras protein signal transduction

0.016281

0.016648

regulation of cellular process

0.016903

Ion binding

Regulation of small GTPase mediated signal transduction

0.017061

Regative regulation of cellular macromolecule biosynthetic process

0.017259

Regulation of developmental process

0.017259

Metal ion binding

0.017719

Endoribonuclease activity, producing 5'-phosphomonoesters

0.018441

NADP metabolic process

0.018441

Cation binding

0.019467

0.019795

Regulation of biological process

0.020303 
Table III. Continued.

\section{GO description}

Negative regulation of cellular biosynthetic process

Negative regulation of nitrogen compound metabolic process

Negative regulation of nucleobase-containing compound metabolic process

Negative regulation of macromolecule biosynthetic process

DNA-directed RNA polymerase II, core complex

Pteridine-containing compound metabolic process

Exonuclease activity

Biological regulation

Heterocycle metabolic process

Cellular aromatic compound metabolic process

Quanyl-nucleotide exchange factor activity

Sulfur compound transmembrane transporter activity

Organic cyclic compound metabolic process

Cellular nitrogen compound biosynthetic process

ARF guanyl-nucleotide exchange factor activity

Regulation of ARF protein signal transduction

ARF protein signal transduction

GDP binding

Hydrolase activity, acting on ester bonds

Regulation of intracellular signal transduction

Transmembrane receptor protein serine/threonine kinase activity

Regulation of multicellular organismal development

Taurine transmembrane transporter activity

Negative regulation of blood vessel morphogenesis

Calcium-dependent protein binding

Taurine:sodium symporter activity

Negative regulation of angiogenesis

Histamine receptor activity

Negative regulation of vasculature development

Neurotransmitter transporter activity

Neurotransmitter:sodium symporter activity

Mannose metabolic process

Organic acid:sodium symporter activity

Hormone receptor binding

Wnt signaling pathway

Nuclear hormone receptor binding

Molecular function regulator

DNA biosynthetic process

Phosphatase regulator activity

Intrinsic component of plasma membrane

Integral component of plasma membrane

DNA topological change

Aspartate family amino acid metabolic process

Signal transduction

Coenzyme biosynthetic process

Pyridine nucleotide biosynthetic process

Pyridine-containing compound biosynthetic process

Nicotinamide nucleotide biosynthetic process

Anatomical structure morphogenesis

Single organism signaling

Cellular response to stimulus

Signaling

\section{P-value}

Number of genes

0.020303

0.020303

0.020303

0.020303

0.021299

0.022568

0.023676

0.02412

0.024922

0.025948

0.02599

0.027145

0.028103

0.028363

0.031456

0.031456

0.031456

0.031599

0.031838

0.031966

0.032389

0.032389

0.034046

0.034046

0.034046

0.034046

0.034046

0.034046

0.034046

0.034554

0.034554

0.034554

0.034554

0.0381

0.0381

0.0381

0.038432

0.039752

0.040667

0.040951

0.040951

0.042894

0.042894

0.042957

0.044016

0.044349

0.044349

0.044349

0.044349

0.044355

0.045164

0.046516

5


Table III. Continued.

\begin{tabular}{lrr}
\hline GO description & P-value & Number of genes \\
\hline Transcription, DNA-templated & 0.048815 & 90 \\
IMP dehydrogenase activity & 0.048989 & 2 \\
Negative regulation of developmental process & 0.048989 & 2 \\
Nucleoside phosphate biosynthetic process & 0.049767 & 13 \\
Nucleotide biosynthetic process & 0.049767 & 13 \\
\hline
\end{tabular}

GO, Gene Ontology.

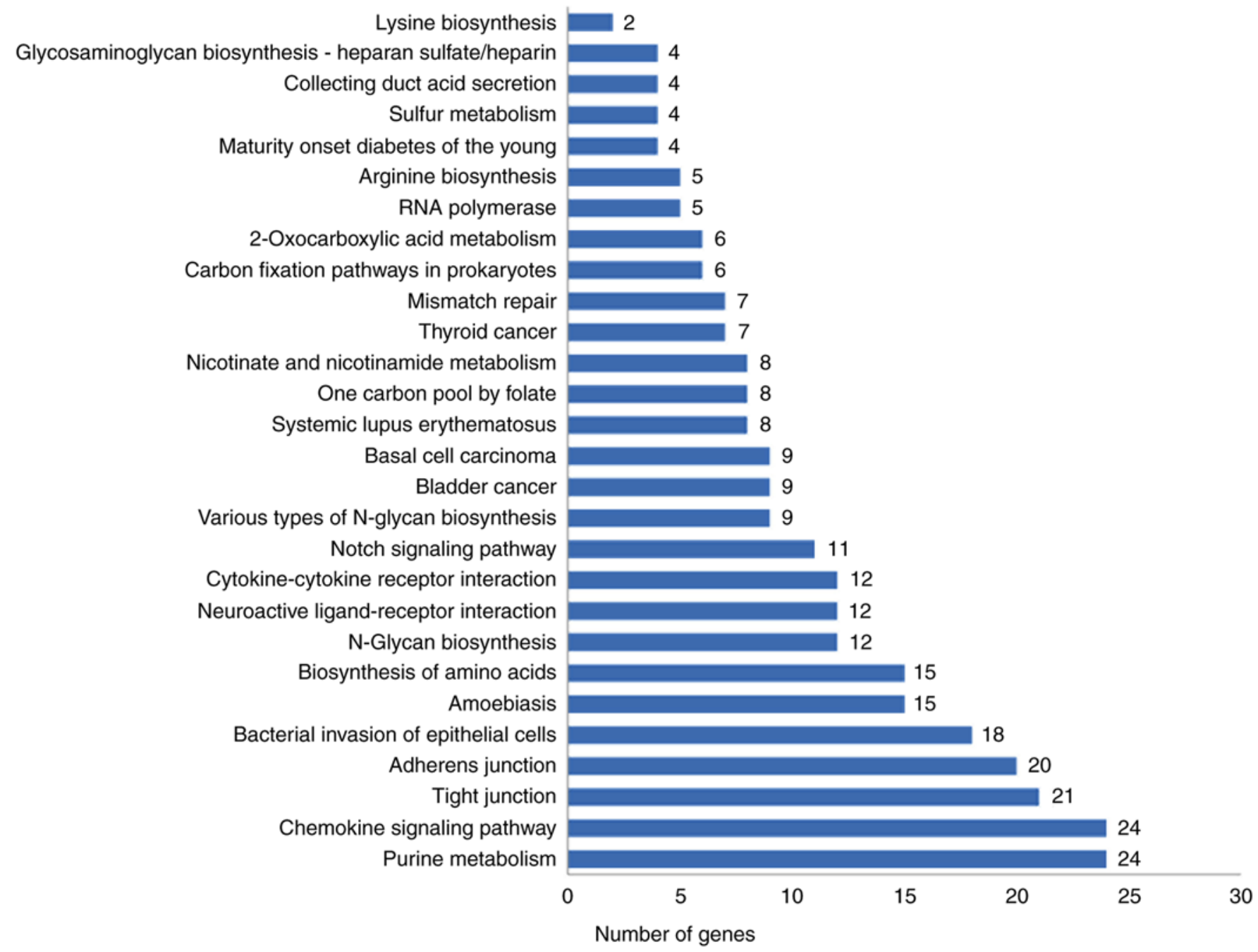

Figure 1. KEGG pathways enriched in response to eleutheroside B1 treatment. Enrichment analysis results of DEGs between the eleutheroside B1 treatment group (PR8 + eleu) and the virus-infected alone group (PR8). DEG, differentially expressed gene; KEGG, Kyoto Encyclopedia of Genes and Genomes.

Bisulfite treatment and DNA methylation analysis. Genomic DNA was extracted from eleutheroside B1-treated and non-treated A549 cells following an influenza virus infection using a DNA Extraction of Cell and Tissue kit (cat. no. GK0122; Generay Biotech Co., Ltd., Shanghai, China). The bisulfite conversion was performed with $1 \mu \mathrm{g}$ genomic DNA using an EpiTect Fast DNA Bisulfite kit (cat. no. 59824; Qiagen China Co., Ltd., Shanghai, China), according to the manufacturer's instructions. The bisulfite-modified DNA was amplified by
PCR with primers that were designed to cover two regions One primer extended from -545 bp upstream and $-213 \mathrm{bp}$ downstream to the transcription start site of MAN2A1, whereas the other extended from -199 bp upstream and $139 \mathrm{bp}$ downstream. For the POLR2A gene, $66 \mathrm{CpG}$ sites ranging from -606 to +476 bp relative to exon 1 in a $\mathrm{CpG}$ island were selected for subsequent analysis, and for the design of primers. Subsequently, the first-stage PCR product was amplified under the following conditions: $95^{\circ} \mathrm{C}$ for $4 \mathrm{~min}$; 40 cycles 


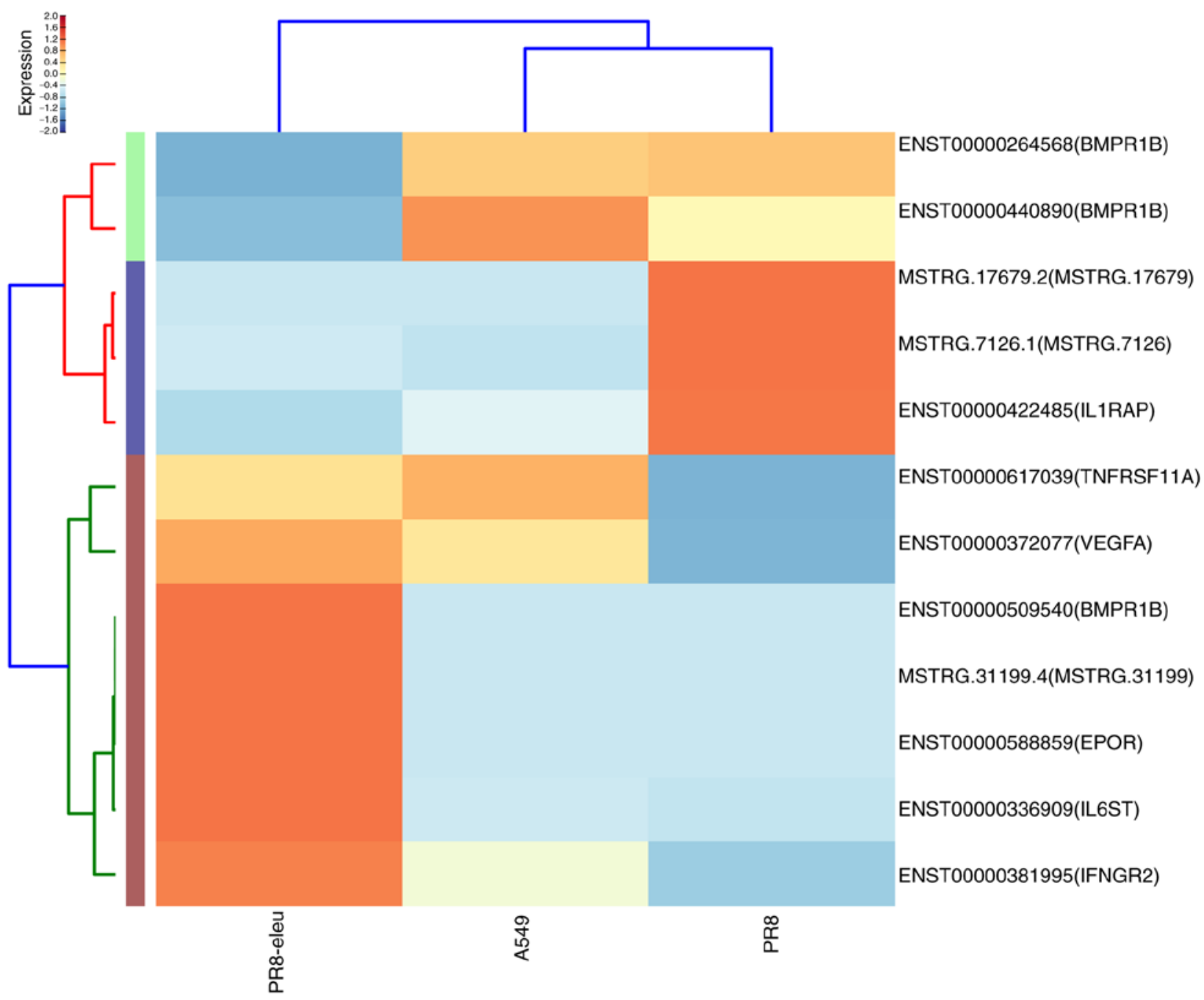

Figure 2. Enrichment analysis results of DEGs regulated by eleutheroside B1 treatment in cytokine-cytokine receptor interactions pathway. The heat-map shows the 12 DEGs that were regulated by eleutheroside B1 treatment among three samples in the cytokine-cytokine receptor interaction pathway (high levels of expression, red; low expression, blue). DEG, differentially expressed gene.

of $94^{\circ} \mathrm{C}$ for $30 \mathrm{sec}, 55^{\circ} \mathrm{C}$ for $30 \mathrm{sec}$, and $72^{\circ} \mathrm{C}$ for $40 \mathrm{sec}$, followed by a final extension at $72^{\circ} \mathrm{C}$ for $5 \mathrm{~min}$. PCR products were purified using a PCR purification kit (cat. no. GK2043; Generay Biotech Co., Ltd.). The PCR products were cloned into the TA cloning vector (cat. no. GV6021; Generay Biotech Co., Ltd.). Ten clones from each donor were sequenced using an M13 reverse primer.

Statistical analysis. All data are expressed as the mean \pm standard deviation of at least three separate experiments. Differences between two groups were analyzed using Student's t-test, whereas differences between multiple groups were analyzed using one-way analysis of variance followed by Fisher's Least Significant Difference post-hoc test. Statistical analyses were performed using SPSS 18.0 (SPSS, Inc., Chicago, IL, USA). $\mathrm{P}<0.05$ was considered to indicate a statistically significant difference.

\section{Results}

Sequencing and alignment. To investigate the molecular mechanism of eleutheroside B1 action against influenza A virus infection, RNA sequencing of influenza A virus-infected human lung epithelial A549 cells, in the presence or absence of eleutheroside B1 treatment, was performed using an Illumina X-ten RNA-seq sequence production system. The RNA sequences were subsequently aligned against the human gene sequences. Three different experimental groups were established: Lung epithelial A549 cells without infection (A549 group), A549 cells infected with influenza strain A/PR8/34/(H1N1) alone (PR8 group), and A549 cells both infected with A/PR8/34/(H1N1) and treated with $100 \mu \mathrm{g} / \mathrm{ml}$ eleutheroside B1 (PR8 + eleu group). At $24 \mathrm{~h}$ after the influenza virus infection, samples were harvested and subjected to library construction and RNA sequencing. An excess of 13 million raw reads for each sample were generated from the constructed RNA sequencing libraries using the Illumina X-ten RNA-seq sequence production system. After stringent data filtering, $34.75 \mathrm{M}$ (97.11\%; A549 group), $33.97 \mathrm{M}$ (95.93\%; PR8 group), or 34.79 M (95.45\%; PR8 + eleu group) sequencing reads could be unambiguously mapped against the reference genome (Table II), which confirmed the high quality of the sequencing of these samples, and a satisfactory variable for subsequent analyses. 


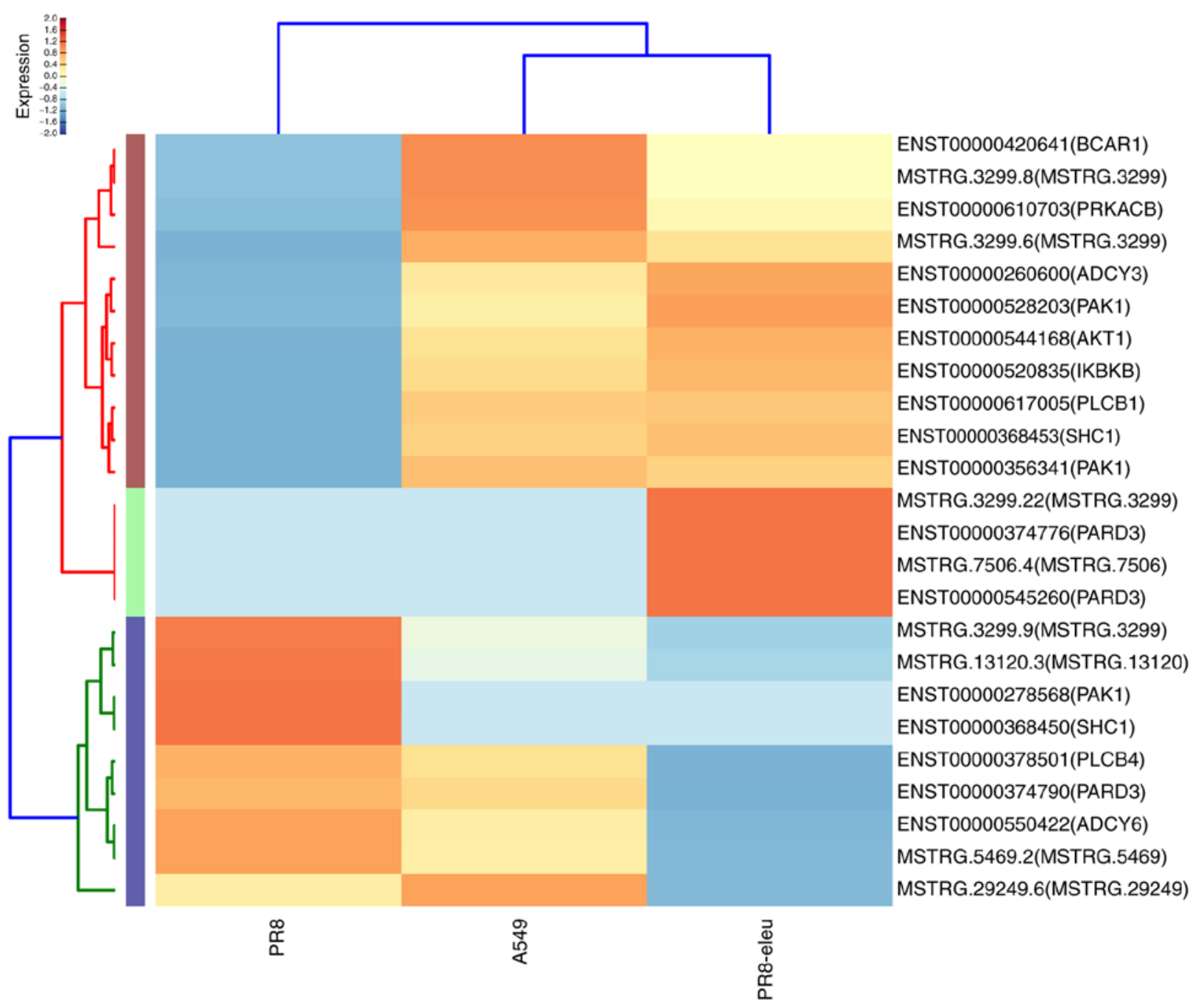

Figure 3. Enrichment analysis results of DEGs regulated by eleutheroside B1 treatment in the chemokine signaling pathway. The heat-map shows the 24 DEGs that were regulated by eleutheroside B1 treatment among three samples in the chemokine signaling pathway (high levels of expression, red; low expression, blue). DEG, differentially expressed gene.

Effect of eleutheroside B1 treatment on pathway regulation in influenza A virus-infected lung epithelial A549 cells. The gene lists generated for influenza A virus-infected human lung epithelial A549 cells in the absence or presence of eleutheroside B1 treatment revealed large differences in the number and the type of genes that were transcriptionally activated. To gain an improved understanding of the host cell response to influenza virus infection at $24 \mathrm{~h}$, the 1,871 DEGs (958 upregulated and 913 downregulated genes) between the PR8 and the PR8 + eleu groups were characterized by performing an enrichment analysis according to biological process, cellular composition and molecular function. GO enrichment analysis indicated that numerous DEGs were involved in molecular function and biological processes, and these results are presented in Table III. The GO enrichment results revealed that eleutheroside B1 recruited molecular function and biological process genes in the host to inhibit the infection of influenza virus. KEGG pathway enrichment analysis suggested that these DEGs were associated with the immune system, glycan biosynthesis and metabolism, signaling molecules and their interaction, transcription (e.g., of the chemokine signaling pathway), various types of $\mathrm{N}$-glycan biosynthesis, cytokine-cytokine receptor interaction, and RNA polymerase function, which are host-response pathways that are activated in response to influenza virus infection (Fig. 1). Twelve DEGs were enriched in cytokine-cytokine receptor interactions. Of these DEGs, bone morphogenetic protein receptor type 1B (BMPR1B), interleukin-6 signal transducer (IL6ST), interferon $\gamma$ receptor 2 (IFNGR2), interleukin-1 receptor-associated protein (IL1RAP) and erythropoietin receptor (EPOR) have been reported to be involved in the host immune response to virus infections (Fig. 2). BMPR1B is a host gene, the levels of which change during the process of influenza virus infection (23), and this was expressed at a 548-fold higher level compared with the PR8 group. IFNGR2 is the upstream molecule in the interferon $\gamma($ IFN- $\gamma)$ signaling pathway, which is affected by the influenza virus (24). Compared with the PR8 group, there was a 1,369-fold upregulation of the IFNGR2 gene in the PR8 + eleu group. EPOR is crucial for the phosphorylation of signal transducer and activator of transcription (STAT) 5 , which acts as an important molecule in the Janus kinase (JAK)-STAT signaling pathway (22). Influenza A virus 


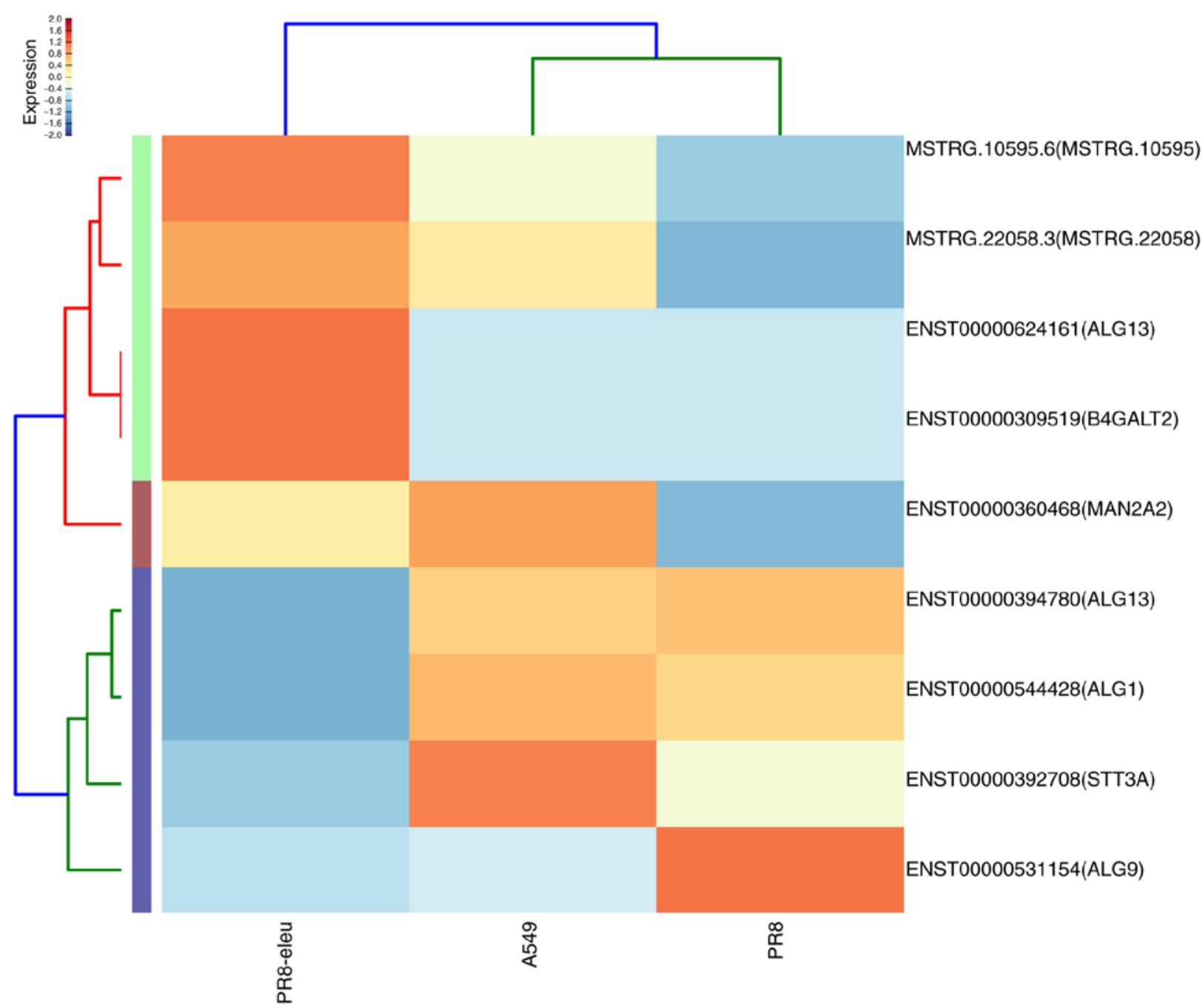

Figure 4. Enrichment analysis results of DEGs regulated by eleutheroside B1 treatment in various N-glycan biosynthesis pathways. The heat-map shows the 9 DEGs that were regulated by eleutheroside B1 treatment among three samples in various types of N-glycan biosynthesis pathway (high levels of expression, red; low expression, blue). DEG, differentially expressed gene.

directly interferes with IFN- $\gamma$-stimulated signal transduction via this pathway, which enables the virus to inhibit IFN- $\gamma$-inducible gene expression (24). In the present study, levels of the EPOR gene were found to be upregulated by 255 -fold. IL1RAP is a co-receptor of the IL-1 receptor (IL1R1) and the IL-33 receptor (ST2), and is required for signaling through both receptor complexes. The inhibition of IL1RAP is also capable of blocking IL-1 signaling, which disrupts the activation of nuclear factor (NF)- $x \mathrm{~B}$ mediated by IL-1 and IL-33, and may inhibit influenza virus-induced pro-inflammatory reaction (25).

Influenza A virus infection in the lung is associated with a robust host inflammatory response and sustained elevated levels of inflammatory immune mediators (26), whereas certain natural product compounds have been demonstrated to exhibit anti-inflammatory effects $(27,28)$. The DEG data associated with the chemokine signaling pathway (Fig. 3) confirmed our previous finding that eleutheroside B1 exhibits anti-inflammatory activity against the influenza virus (14). The DEGs identified in the N-glycan biosynthesis pathway suggest other ways in which eleutheroside B1 may work against the influenza virus. In the $\mathrm{N}$-glycan biosynthesis pathway, there are only a small number of glycosyltransferases catalyzing different glycosidic linkages on different $\mathrm{N}$-glycans that exert a crucial role in cellular activity (29). The synthesis of influenza virus hemagglutinins has been reported to be involved in this process (30). In the present study, 12 enriched DEGs were identified in the major $\mathrm{N}$-glycan biosynthesis pathway, 9 enriched DEGs were found in various other types of $\mathrm{N}$-glycan biosynthesis pathways, and 3 genes were found in other glycan degradation pathways (Fig. 4), all of which are involved in glycan biosynthesis and metabolism. These included: UDP- $N$-acetylglucosaminyltransferase subunit (ALG13), mannosidase $\alpha$ class 2A member 2 (MAN2A2), mannosidase $\alpha$ class $2 \mathrm{C}$ member 1 (MAN2C1), chitobiosyldiphosphodolichol $\beta$-mannosyltransferase (ALG1), and $\alpha-1,2-$ mannosyltransferase (ALG9). MAN2C1 has dual functions: One is associated with glycan catabolism, whereas the other is in apoptotic signaling, and its downregulation has been reported to delay cancer growth by inducing either mitotic arrest or apoptosis (31). MAN2C1 overexpression also results in synthesis of the non-glucosylated Man9GlcNAc2 oligosaccharide precursor, which is transferred to the protein substrates more inefficiently, thereby resulting in protein 
Table IV. Score of molecular docking.

\begin{tabular}{lrcc}
\hline Protein & Total_Score & CSCORE & UNIFIED-CECORER \\
\hline MAN2A1 & 11.3029 & 5 & 3 \\
POLR2A & 9.0133 & 5 & 2
\end{tabular}

MAN2A1, mannosidase $\alpha$ class II member 1; POLR2A, RNA polymerase II subunit A.

underglycosylation (32). In the present study, MAN2C1 was upregulated 9-fold following eleutheroside B1 treatment.

RNA synthesis is a fundamental process in gene expression, and POLR2A, a housekeeping gene coding for the large subunit of RNA polymerase II (RNAPII) in RNA biosynthesis (33), is a host factor involved in RNAPII-dependent transcription and mRNA processing of the influenza virus (34). The RNA sequencing results of the present study revealed that POLR2A was downregulated by 16,384 -fold following eleutheroside B1 treatment.

POLR2A may interact with eleutheroside B1, as determined from the molecular docking assay. Over the course of the last three decades, specific inhibitors of certain enzymes associated with the N-glycan biosynthesis pathway have demonstrated their potential for antiviral and tumor therapy (35). Golgi MAN2A1 is a key enzyme, which acts late in the N-glycan biosynthesis pathway and is a target in the development of anticancer and antiviral therapies (36). Mannostatin A effectively blocked processing of the influenza viral hemagglutinin in cultured MDCK cells, causing the accumulation of hybrid-type protein-linked oligosaccharides, a result which is in agreement with blocking Golgi mannosidase II (36). MAN2A1 inhibitors are also extracted from plant sources and, therefore, the present study aimed to investigate whether MAN2A1 may be a potential target of eleutheroside B1. However, we did not identify the structure of human MAN2A1 and is not available in databases; therefore, the structure of D. melanogaster MAN2A1 was used in the present study. In the initial results, D. melanogaster MAN2A1 was docked with eleutheroside B1. In addition, the crystal structure of human MAN2A1 was established through homology modeling, and this predicted structure was used for docking assays with eleutheroside B1. Furthermore, a previous study by our research group had shown that eleutheroside B1 inhibited the polymerase activity of influenza virus (14). POLR2A is an important host factor that is involved in the polymerase activity of influenza virus, and is downregulated by eleutheroside B1. Therefore, POLR2A was also selected for further investigation.

Small molecules were docked to these selected proteins, and the docking scores were analyzed. In general, a compound that has a high docking score with the protein (Total Score and CScore) indicates that the compound may have potential activities against the targeted receptor (37). From the results of the docking study, it was possible to determine that the selected molecules exhibited good binding affinity towards the homologous proteins in the model. The specific scores are listed in Table IV.
To determine its potency, the best-docked conformation of eleutheroside B1 was analyzed, and this molecular compound was found to bind to the inside of D. melanogaster MAN2A1(3BVT) and human POLR2A(3D9N), based upon the hydrogen and hydrophobic interactions. If such features are identified, it demonstrates that the compound in question may be responsible for mediating biological activities. The docked conformations of eleutheroside B1 in the D. melanogaster MAN2A1(3BVT) and human POLR2A(3D9N) structures are illustrated in Figs. 5 and 6, respectively. The interaction analysis revealed that there are 13 hydrogen bonds formed by eleutheroside $\mathrm{B} 1$ in the binding site of D. melanogaster MAN2A1(3BVT), and four hydrogen bonds formed by eleutheroside B1 in the binding site of human POLR2A(3D9N), together with two carbon-hydrogen bonds and two conventional hydrogen bonds. Other interactions were also investigated, including van der Waals' forces, which contact the surrounding residues in the binding site of bovine serum antigen, including Arg-893, Leu-925, Arg-565, Leu-568, Arg-777, Glu-753, Trp-531, Arg-427 and Asp-930. Inspection of the molecular interactions revealed that hydrogen bonds and van der Waals' forces were the major factors influencing the stabilities of the eleutheroside B1-MAN2A1 and the eleutheroside B1-POLR2A complexes, which are illustrated in Figs. 5 and 6, respectively.

MAN2A1(3BVT) in this docking assay belongs to D. melanogaster, which has high sequence identity with human MAN2A1 (41\% identity; 61\% similarity) (38). A predicted crystal structure for the human MAN2A1 was also generated through homology modeling with docked eleutheroside $\mathrm{B} 1$, however this had a lower docking score (data not shown). Since the protein POLR2A is associated with a higher molecular docking score and is also of human origin, this protein was identified as a target protein for eleutheroside $\mathrm{B} 1$, and further experimental verification was performed at the cellular level.

Eleutheroside B1 modifies the CPG methylation levels of the POLR2A and MAN2Al genes. Even in the molecular docking assay, human MAN2A1 did not match precisely with eleutheroside B1; however, the possibility of their biological interaction could not be excluded. Therefore, MAN2A1 and POLR2A were selected to examine the $\mathrm{CpG}$ methylation levels modified by eleutheroside $\mathrm{B} 1$. $\mathrm{CpG}$ islands were identified on the POLR2A and MAN2A1 promoters by sequence analysis (http://www.urogene.org/cgi-bin/methprimer/methprimer.cgi; Fig. 7). To investigate whether eleutheroside B1 modifies DNA methylation of POLR2A and MAN2A1, bisulfite-sequencing PCR (BSP) was performed to quantitatively analyze the methylation levels of $\mathrm{CpG}$ sites in these genes in A549 cells incubated with or without eleutheroside B1 following infection with $\mathrm{A} / \mathrm{PR} / 8 / 34$ (H1N1). Ten clones were selected for the analysis of each $\mathrm{CpG}$ site. The BSP analysis revealed that the average proportion of methylated $\mathrm{CpGs}$ of the POLR2A gene increased significantly $(\mathrm{P}<0.05)$ in A549 cells treated with eleutheroside B1 compared with the PR8 group (Fig. 7). However, no significant differences were identified for the proportion of methylated CpGs of the MAN2A1 gene between A549 cells with or without eleutheroside $\mathrm{B} 1$ treatment following infection with A/PR/8/34 (H1N1) (data not shown). 

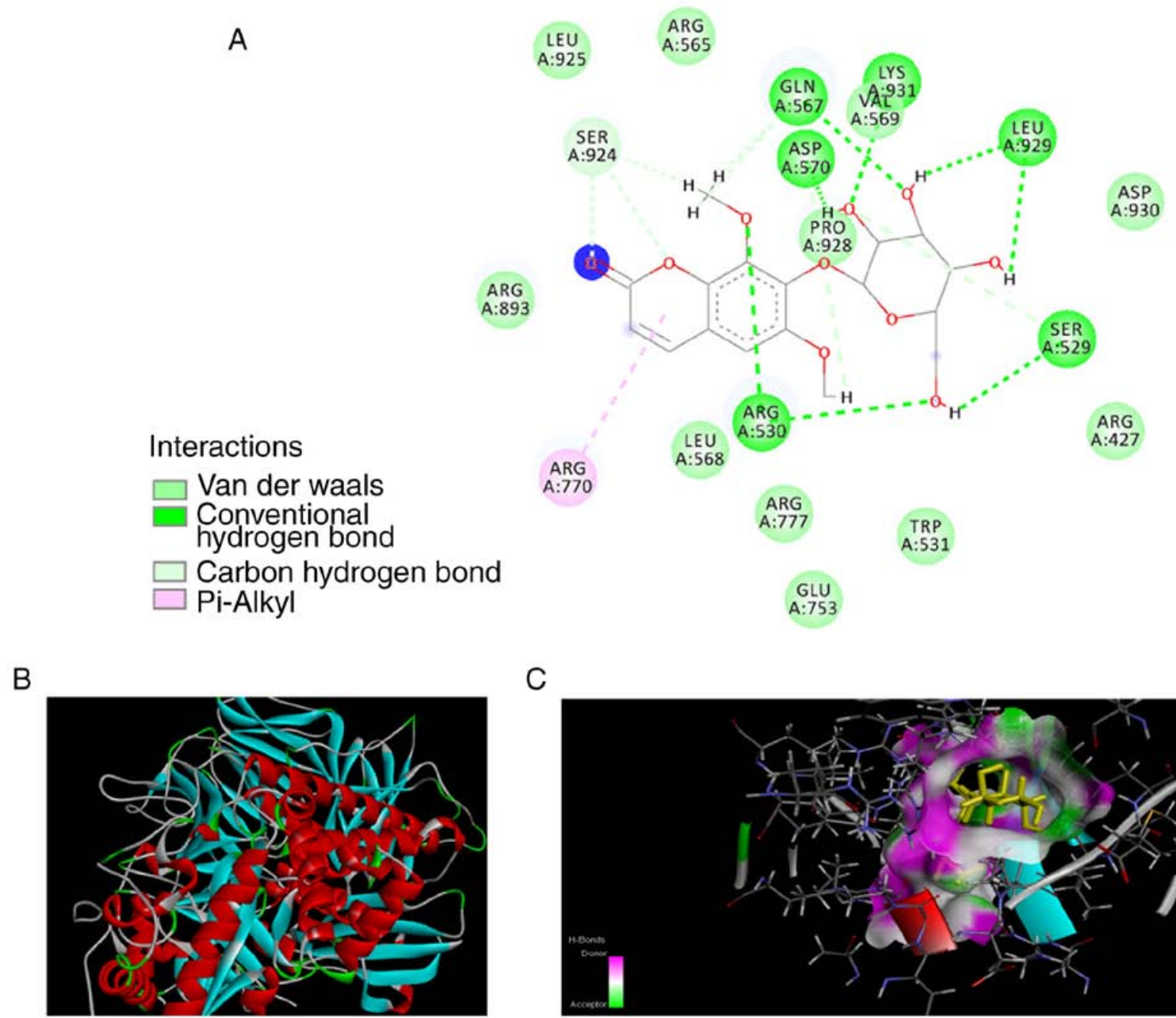

C

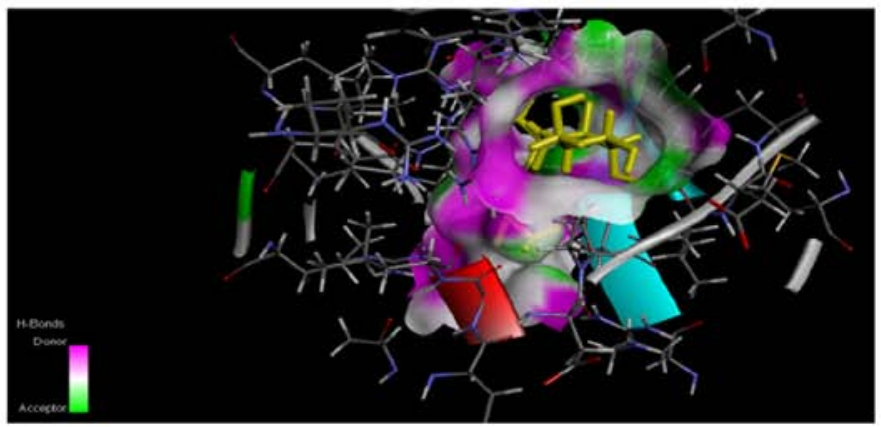

Figure 5. Docking results of eleutheroside B1 and MAN2A1. (A) The predicted three-dimensional structure of eleutheroside B1 (rendered by sticks) binding to MAN2A1. (B) The binding interaction of MAN2A1 and the surrounding residues, in which hydrogen donors are shown in pink and hydrogen acceptors are shown in green. The rest of the surface is white. (C) Details of the interaction between eleutheroside B1 and MAN2A1, as well as the hydrophobicity, which is shown in a different color, from the highest lipophilic area (brown) to the highest hydrophilic area (blue). MAN2A1, mannosidase $\alpha$ class II member 1.

mRNA expression of host genes and virus genes are influenced by eleutheroside B1 treatment in A549 cells. To identify genes involved in novel pathways, such as various types of $\mathrm{N}$-glycan biosynthesis and RNA polymerase function, the expression levels of host genes (MAN2A2, POLR2A) were detected. In glycan biosynthesis and metabolism, MAN2A1, MAN2A2, and MAN2C1 were identified as the important targets. MAN2A1 did not display a potential interaction with eleutheroside B1; MAN2A2, however, was involved in the various types of $\mathrm{N}$-glycan biosynthesis pathways, whereas MAN2C1 was involved in other glycan degradation pathways. POLR2A demonstrated a marked potential interaction with eleutheroside B1 in the present study, and significant levels of expression were observed following influenza infection in A549 cells treated with eleutheroside B1, and influenza infection of the A549 cells in the RNA sequencing studies. Therefore, MAN2A2 and POLR2A were selected for determination of their expression levels. In addition, virus genes (PA, PB1, PB2, HA) in A/PR/8 (0.1 MOI)-infected A549 cells were also subjected to mRNA expression studies. The results demonstrated that the expression of host genes (MAN2A2, POLR2A) and virus genes (PA, PB1, PB2, HA) were decreased following eleutheroside $\mathrm{B} 1$ treatment at a concentration of $100 \mu \mathrm{g} / \mathrm{ml}$ (Fig. 8). The expression levels of the influenza virus ribonucleoprotein (RNP) genes (PA, PB1, PB2) were downregulated by eleutheroside $\mathrm{B} 1$, a finding which was consistent with the results of a previous study, showing that eleutheroside B1 may target the influenza virus RNP and RNA polymerases in the host (14).

\section{Discussion}

Since a comprehensive analysis of the mechanisms underlying specific agents of TCM acting against influenza virus at the molecular level is difficult, RNA sequencing approaches may compensate for such draw-backs, and provide a systematic analysis for the study of TCM pharmacology in order to identify the key molecular events that are linked with their efficacy (18).

In the RNA sequencing experiments of the present study, the 1,871 DEGs identified between the PR8 and PR8 + eleu groups were characterized by performing an enrichment analysis according to biological processes, cellular composition, and molecular function. These DEGs were involved 


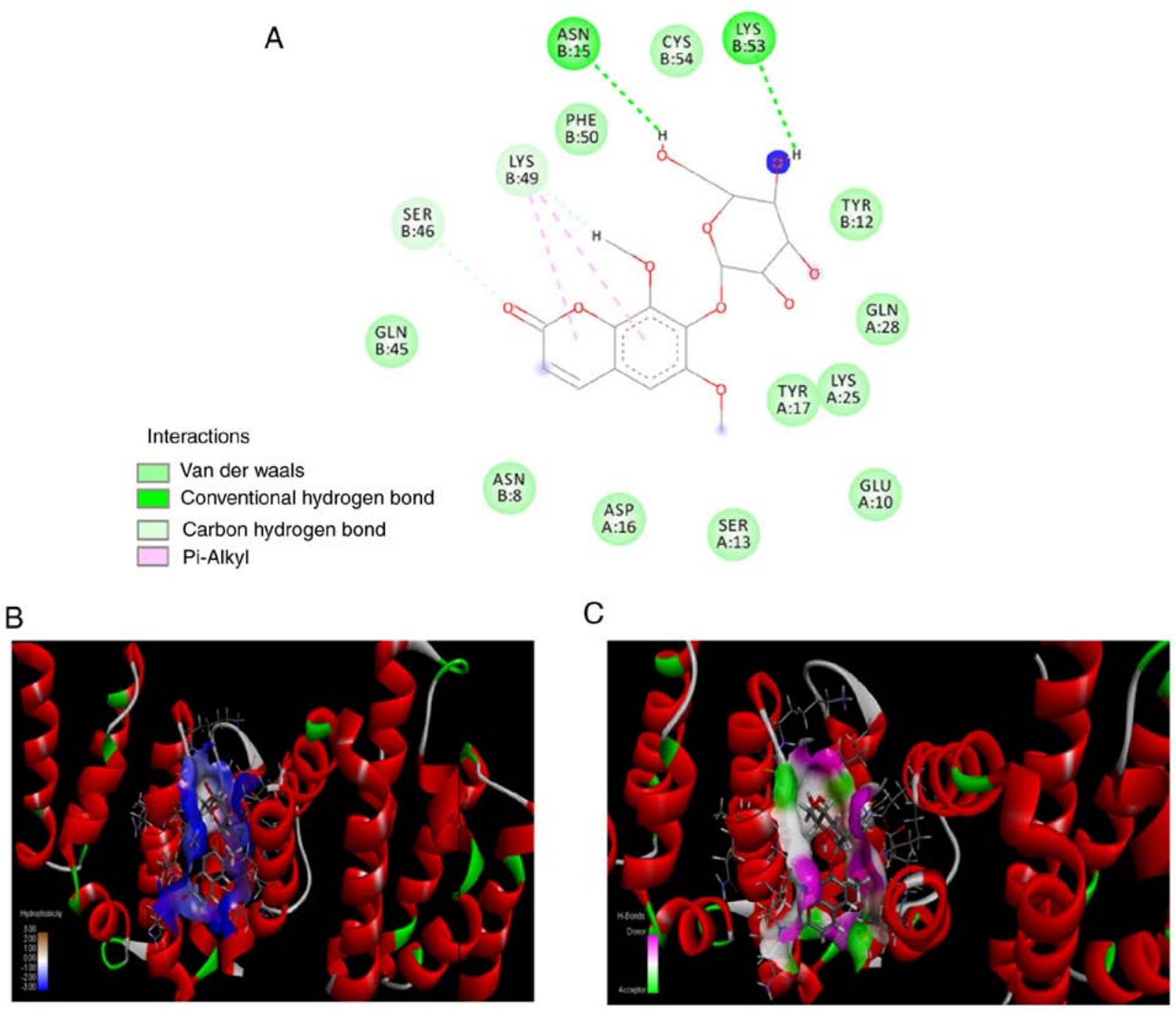

B

Figure 6. Docking results of eleutheroside B1 and POLR2A. (A) The predicted three-dimensional structure of eleutheroside B1 (rendered in sticks) binding to POLR2A. (B) The interaction between eleutheroside B1 and POLR2A, as well as the hydrophobicity, which is shown in a different color, from the highest lipophilic area (brown) to the highest hydrophilic area (blue). (C) The binding interaction of POLR2A and the surrounding residues, in which hydrogen donors are shown in pink and hydrogen acceptors are shown in green. The rest of the surface is white. POLR2A, RNA polymerase II subunit A.

in various types of $\mathrm{N}$-glycan biosynthesis, the chemokine signaling pathway, cytokine-cytokine receptor interaction, and RNA polymerase function, which are host responses to influenza viral infection. The biosynthesis of $\mathrm{N}$-glycans is very complex in mammals, as is the glycosylation-mediated quality control of protein folding by N-glycans (39). Glycosylation has become an area of intensive study in recent years, due to its ability to impact viral biology. A previous study demonstrated that $\mathrm{N}$-glycosylation of the influenza hemagglutinin serves an important role in the life cycle of the influenza virus (35). The present RNA sequencing results demonstrated that certain DEGs, including ALG13, MAN2A2, MAN2C1, ALG1, and ALG9, were enriched in glycan biosynthesis and metabolism. MAN2C1 overexpression also results in the synthesis of non-glucosylated Man9GlcNAc2 oligosaccharide precursor, which is transferred to the protein substrates rather inefficiently, thereby resulting in suboptimal protein glycosylation. In the present study, MAN2C1 was upregulated by 9-fold following eleutheroside $\mathrm{B} 1$ treatment. This finding indicated that eleutheroside $\mathrm{B} 1$ may regulate the $\mathrm{N}$-glycosylation of the influenza hemagglutinin via this pathway, although further studies are required to confirm this phenomenon.

Cytokines are soluble extracellular proteins or glycoproteins that are crucial intercellular regulators and are involved in innate, as well as adaptive, inflammation of host defenses, cell growth, differentiation, cell death, angiogenesis, development and repair processes (40). Cytokines and cytokine receptor interaction networks are regarded as essential components of inflammation (41). In the current RNA sequencing studies, 12 DEGs were enriched in cytokine-cytokine receptor interactions. These DEGs included BMPR1B, IL6ST, IFNGR2, IL1RAP, and EPOR, which have been reported to be involved in host immune response to viral infections. IL-6ST encodes membrane glycoprotein 130 (gp130). It is the common signal transducing component of the IL6 cytokine receptor family, which forms complexes with the ligand-binding receptor subunits of multiple IL6 cytokine family members, serving as an important activator of JAK-STAT signaling. IL-6ST has also been reported to be involved in the host response for the infection of influenza virus $(42,43)$. These results suggested that eleutheroside B1 may inhibit influenza virus through 

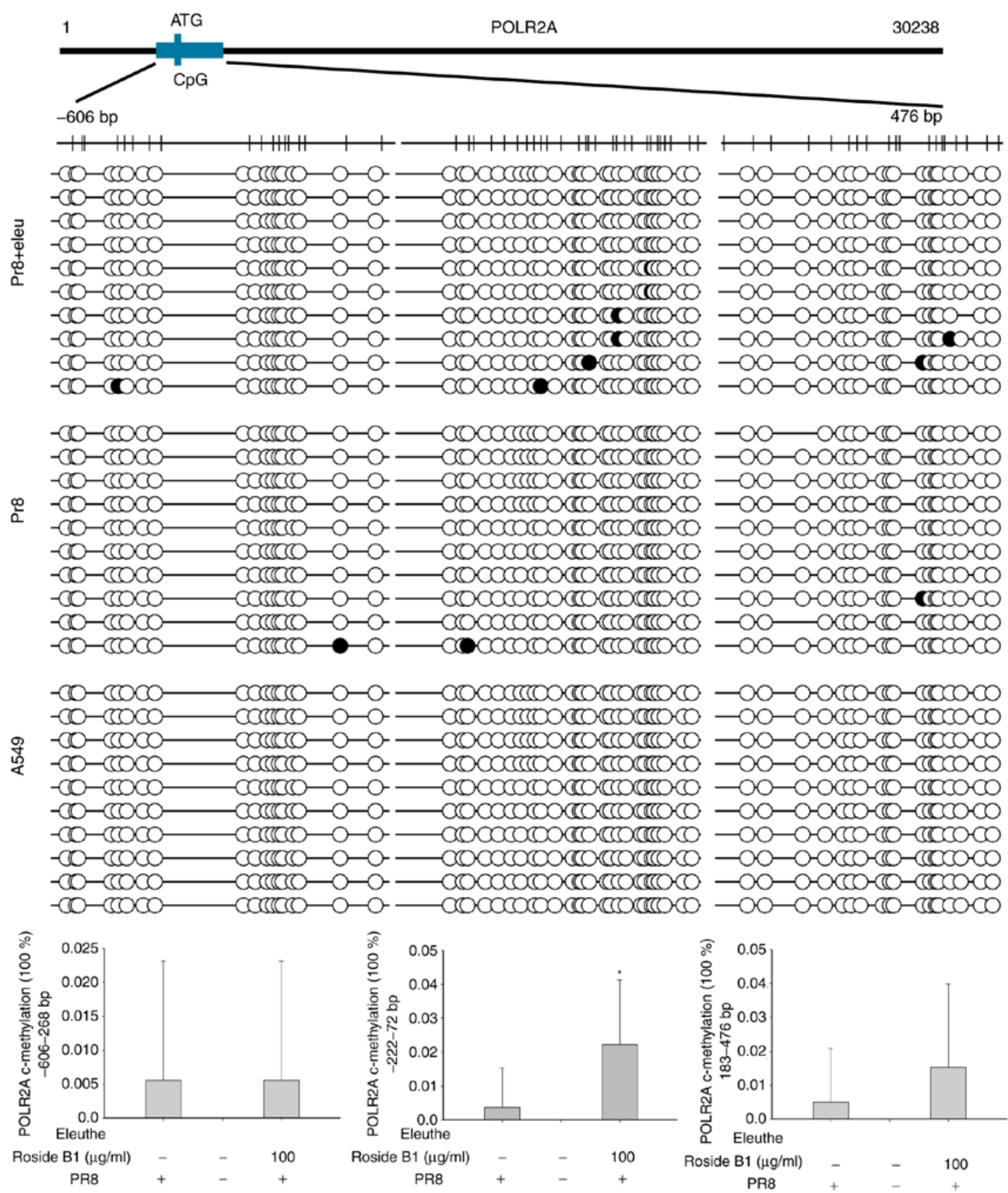

Figure 7. Prediction of $\mathrm{CpG}$ islands and effects of eleutheroside $\mathrm{B} 1$ on DNA methylation of POLR2A in virus-infected A549 cells. POLR2A, RNA polymerase II subunit A. The white circles are unmethylated sites and the black circles are methylated sites. ${ }^{*} \mathrm{P}<0.05$ compared with the PR8 group.

cytokine and cytokine receptor interaction networks, although more evidence is required to conclusively demonstrate this finding.

Chemokines are small soluble molecules that regulate cellular homing through molecular gradients (44). A previously published study reported that the chemokines, C-C motif chemokine ligand 2 (CCL2)/monocyte chemoattractant protein 1 (MCP-1), C-X-C motif chemokine ligand 8 (CXCL8)/interleukin 8 (IL8), CXCL9/monokine induced by interferon- $\gamma$ (MIG), and CXCL10/interferon $\gamma$-induced protein 10 (IP-10), are also associated with mortality caused by human and avian influenza viral infections (45). In the RNA sequencing results of the present study, certain DEGs were also identified in the chemokine signaling pathway, a finding which was consistent with our previous study showing that eleutheroside B1 exhibited anti-inflammatory activity against the influenza virus (14).

The influenza virus polymerase performs numerous functions during the virus' life cycle, suggesting that many cellular factors interact with this complex and are required for the viral genome's transcription and replication. POLR2A is one of the influenza virus polymerase-interacting proteins, and is required for viral replication and transcriptional activity of the viral polymerase (34). In the RNA sequencing results, the levels of POLR2A were downregulated by 21,007 -fold [ $\log F C$ $(\mathrm{PR} 8+$ eleu/PR8 $)=-14.3585910971]$ following eleutheroside B1 treatment. The influenza virus transcribes and replicates its genome inside the nucleus of infected cells, a process that requires viral RNA polymerase, including the three subunits PA, PB1, and PB2, as well as host cell factors to transcribe 

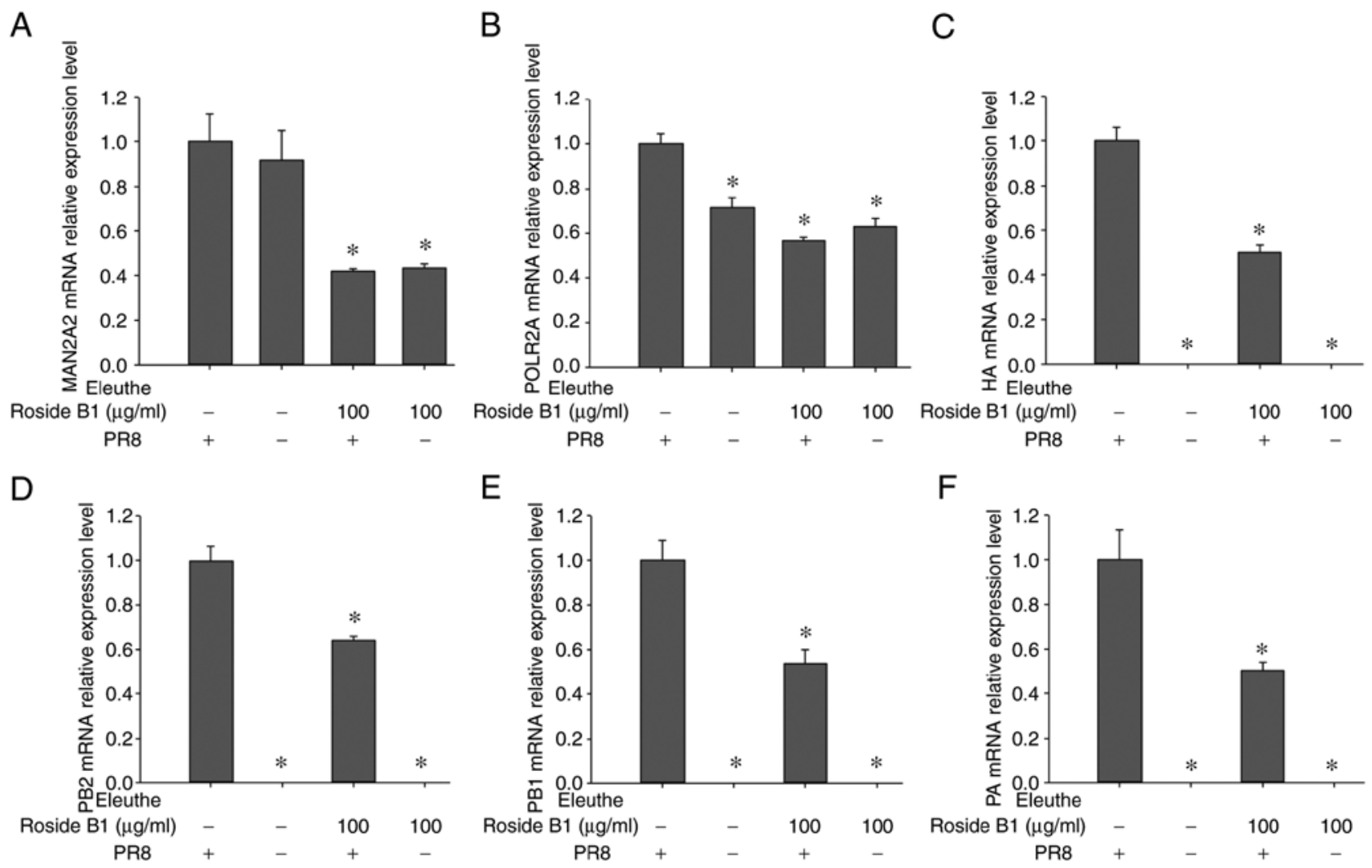

Figure 8. Effect of eleutheroside B1 on host and viral gene expression. (A and B) mRNA expression levels of the host genes (MAN2A2, POLR2A) and (C-F) the viral genes (HA, PB2, PB1, PA) was examined in the virus-infected A549 cells, with or without eleutheroside B1 treatment. "P<0.05 compared with the PR8 group. MAN2A1, mannosidase $\alpha$ class II member 1; POLR2A, RNA polymerase II subunit A.

and replicate the viral genome. The cellular transcription factor POLR2A is required for virus replication and the transcriptional activity of the viral polymerase. A previous study demonstrated that the depletion of POLR2A could reduce by 2 -fold the viral polymerase transcription of the influenza virus (34). In the current transcriptome data, eleutheroside B1 treatment also reduced the expression of POLR2A, which demonstrated that POLR2A may be a potential drug target for the inhibition of influenza virus. This result was consistent with our previous finding that eleutheroside B1 inhibited RNP mRNA expression and transcriptional activity of the viral polymerase (14).

Molecular docking methodology explores the behavior of small molecules in the binding pocket of a target protein, and calculates the ability of the compounds to act against a particular target (and their specificity). In modern drug discovery, molecular docking methodology serves an important role in predicting the orientation of the ligand, and provides potential leads for researchers to identify potential drugs and drug targets (46). In the molecular docking results in the present study, eleutheroside $\mathrm{B} 1$ was found to bind to the inside of the D. melanogaster MAN2A1(3BVT) and human POLR2A, but this was not the case for the predicted crystal structure of human MAN2A1. These findings indicated that POLR2A may be the potential target for the eleutheroside B1 against influenza virus infections in humans, which was in accordance with the RNA sequencing results.

MAN2A2 is an important enzyme in the N-glycan biosynthesis pathway, and its proper functioning is required for the glycosyltransferases of influenza virus hemagglutinins (36). POLR2A is a housekeeping gene in RNA polymerase II-dependent transcription in hosts, and it is involved in the mRNA processing of influenza virus (33). PA, PB1, PB2, HA are four RNA segments of the influenza virus genome that are crucial for the genome-packaging process of influenza virus (47). Similar to human genes, influenza virus must also pass its genome accurately on to the next generation to ensure the survival of the species (48). The results of the RT-qPCR assay revealed that the mRNA expression levels of MAN2A2, POLR2A, PA, PB1, PB2, and HA, which are principally involved in viral RNP function and virus replication, were all downregulated following eleutheroside B1 treatment. Even in the cells receiving treatment with eleutheroside $\mathrm{B} 1$ alone (i.e., no virus), effects on the expression levels of MAN2A2 and POLR2A were also observed. These results indicated that eleutheroside B1 may affect certain factors associated with the $\mathrm{N}$-glycan biosynthesis pathway and mRNA processing in the host, which leads to the inhibition of the production of influenza virus proteins.

Through recruiting proteins involved in gene repression or inhibiting the binding of transcription factors to DNA, DNA methylation is involved in the regulation of gene expression, mRNA splicing, and genomic stability (49). In general, DNA methylation may block the expression of a gene (50). DNA methylation analysis revealed that eleutheroside $\mathrm{B} 1$ increased the average proportion of methylated $\mathrm{CpGs}$ of the POLR2A gene significantly $(\mathrm{P}<0.05)$ in A549 cells with influenza virus infection, compared with the virus control cells. On the basis 

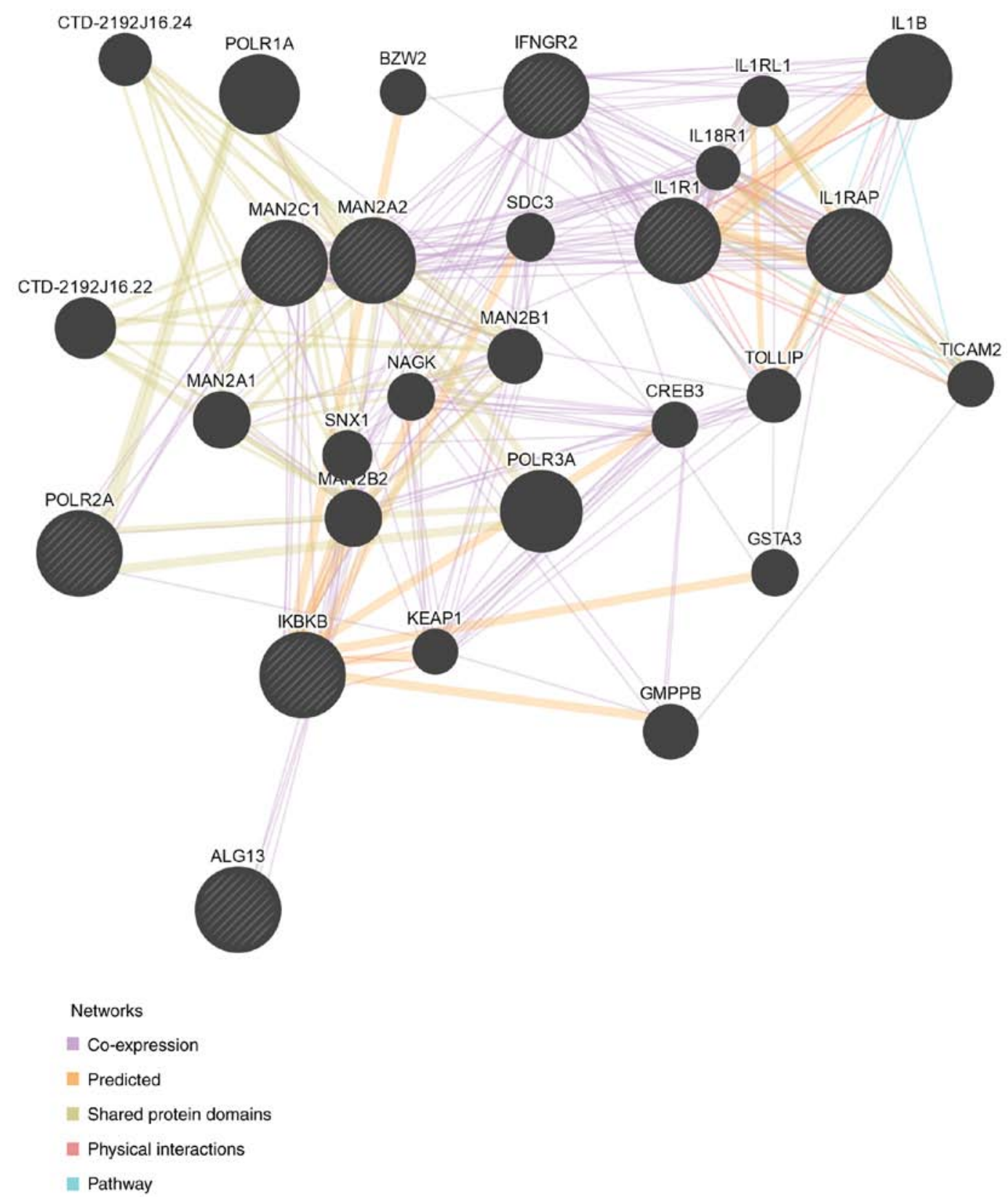

Figure 9. Protein interaction map for differentially expressed genes in target pathways. The map was constructed using the String website (https://string-db. $\operatorname{org} /)$.

of our previous study (14) and the results of the present study, it can be hypothesized that eleutheroside B1 may affect the POLR2A gene DNA methylation pattern to inhibit the production of the influenza virus genome. For the D. melanogaster MAN2A1(3BVT), the molecular docking results demonstrated that it was a good match with eleutheroside B1, but this was not true for the human MAN2A1. Even in the DNA methylation analysis, the DNA methylation levels of human MAN2A1 gene were not influenced by eleutheroside B1 treatment. Therefore, the POLR2A gene is more likely to be the target of eleutheroside B1 compared with the MAN2A1 gene. However, additional studies are required in order to confirm the detailed mechanism of action.

In conclusion, using RNA sequencing technology, the present study demonstrated that eleutheroside B1 may inhibit influenza virus via the chemokine signaling pathway, cyto- kine-cytokine receptor interactions, $\mathrm{N}$-glycan biosynthesis, and RNA polymerase, and that several DEGs involved in these pathways are interconnected as a part of a network, as illustrated in Fig. 9. The changes in the chemokine signaling pathway and in cytokine-cytokine receptor interactions revealed in the present study are consistent with our previous study, which demonstrated that the expression levels of several cytokines were all downregulated by eleutheroside B1 (14). Previous studies have also reported that compounds extracted from herbs exert a role in the inflammatory process, and influence the immune system for the prevention of infectious disease $(51,52)$. In the present study, it was observed that eleutheroside B1 targeted the POLR2A gene in order to affect the expression of viral polymerase. Therefore, eleutheroside B1 may be a promising agent for the prevention and treatment of influenza A virus. 


\section{Acknowledgements}

We would like to thank Dr Richard H. Finnell for his help at language editing.

\section{Funding}

This work was supported by the National Natural Science Foundation of China (grant no. U1502226), the Engineering Technology Research Center (Development) of Guangdong general universities (grant no. GCZX-A1408), and a grant from Guangzhou Municipal Science and Technology Program-Technology Benefiting Special (grant no. 2014Y2-00031).

\section{Availability of data and materials}

The analyzed datasets generated during the study are available from the corresponding author on reasonable request.

\section{Authors' contributions}

WY, CZ, JH and YW performed the experiments, analyzed the data, prepared figures and tables; WZ, XH and XL contributed to analyze data and prepare figures. WY and YW were involved in the drafting of the manuscript. YW and XW designed the study and reviewed drafts. All authors read and approved the final manuscript.

\section{Ethics approval and consent to participate}

Not applicable.

\section{Patient consent for publication}

Not applicable.

\section{Competing interests}

The authors declare that they have no competing interests.

\section{References}

1. Wu W, Li R, Li X, He J, Jiang S, Liu S and Yang J: Quercetin as an antiviral agent inhibits influenza a virus (IAV) entry. Viruses 8: E6, 2015.

2. Webster RG, Bean WJ, Gorman OT, Chambers TM and Kawaoka Y: Evolution and ecology of influenza A viruses. Microbiol Rev 56: 152-179, 1992.

3. Yoon SW, Webby RJ and Webster RG: Evolution and ecology of influenza A viruses. Curr Top Microbiol Immunol 385: 359-375, 2014.

4. Moss RB, Davey RT, Steigbigel RT and Fang F: Targeting pandemic influenza: A primer on influenza antivirals and drug resistance. J Antimicrob Chemother 65: 1086-1093, 2010.

5. Deyde VM, Xu XY, Bright RA, Shaw M, Smith CB, Zhang Y, Shu Y, Gubareva LV, Cox NJ and Klimov AI: Surveillance of resistance to adamantanes among influenza $\mathrm{A}(\mathrm{H} 3 \mathrm{~N} 2)$ and $\mathrm{A}(\mathrm{H} 1 \mathrm{N1})$ viruses isolated worldwide. J Infect Dis 196: 249-257, 2007.

6. Yen HL, McKimm-Breschkin JL, Choy KT, Wong DD, Cheung PP, Zhou J, Ng IH, Zhu H, Webby RJ, Guan Y, et al: Resistance to neuraminidase inhibitors conferred by an R292K mutation in a human influenza virus $\mathrm{H} 7 \mathrm{~N} 9$ isolate can be masked by a mixed $\mathrm{R} / \mathrm{K}$ viral population. mBio 4: e00396-13, 2013.
7. Lin TJ, Lin CF, Chiu CH, Lee MC and Horng JT: Inhibition of endosomal fusion activity of influenza virus by Rheum tanguticum (da-huang). Sci Rep 6: 27768, 2016.

8. Khan S, Riaz N, Afza N, Malik A, Aziz-ur-Rehman, Iqbal L and Lateef M: Antioxidant constituents from Cotoneaster racemiflora. J Asian Nat Prod Res 11: 44-48, 2009.

9. Matos MJ, Vazquez-Rodriguez S, Santana L, Uriarte E, Fuentes-Edfuf C, Santos Y and Muñoz-Crego A: Looking for new targets: Simple coumarins as antibacterial agents. Med Chem 8: 1140-1145, 2012

10. Nakamura T,KodamaN, Oda M, Tsuchiya S, Arai Y,KumamotoT, Ishikawa T, Ueno $\mathrm{K}$ and Yano S: The structure-activity relationship between oxycoumarin derivatives showing inhibitory effects on iNOS in mouse macrophage RAW264.7 cells. J Nat Med 63: 15-20, 2009.

11. Lopez-Gonzalez JS, Prado-Garcia H, Aguilar-Cazares D, Molina-Guarneros JA, Morales-Fuentes J and Mandoki JJ: Apoptosis and cell cycle disturbances induced by coumarin and 7-hydroxycoumarin on human lung carcinoma cell lines. Lung Cancer 43: 275-283, 2004.

12. McKee TC, Covington CD, Fuller RW, Bokesch HR, Young S, Cardellina II JH, Kadushin MR, Soejarto DD, Stevens PF, Cragg GM and Boyd MR: Pyranocoumarins from tropical species of the genus Calophyllum: A chemotaxonomic study of extracts in the National Cancer Institute collection. J Nat Prod 61: 1252-1256, 1998.

13. Fan L, Wang Y, Liang N, Huang XJ, Li MM, Fan CL, Wu ZL, $\mathrm{Li}$ YL and Ye WC: Chemical constituents from the roots and stems of erycibe obtusifolia and their in vitro antiviral activity. Planta Med 79: 1558-1564, 2013.

14. Wang Y, Yan W, Chen Q, Huang W, Yang Z, Li X and Wang X: Inhibition viral RNP and anti-inflammatory activity of coumarins against influenza virus. Biomed Pharmacother 87: 583-588, 2017.

15. Brahmachari G: Discovery and development of antidiabetic agents from natural products. Elsevier Inc, Waltham, MA, 2016.

16. Ranaware PB, Mishra A, Vijayakumar P, Gandhale PN, Kumar H, Kulkarni DD and Raut AA: Genome wide host gene expression analysis in chicken lungs infected with avian influenza viruses. PLoS One 11: e0153671, 2016.

17. Zou W, Chen D, Xiong M, Zhu J, Lin X, Wang L, Zhang J, Chen L, Zhang $\mathrm{H}$, Chen $\mathrm{H}$, et al: Insights into the increasing virulence of the swine-origin pandemic H1N1/2009 influenza virus. Sci Rep 3: 1601, 2013.

18. Zhou B, Li J, Liang X, Yang Z and Jiang Z: Transcriptome profiling of influenza A virus-infected lung epithelial (A549) cells with lariciresinol-4- $\beta$-D-glucopyranoside treatment. PLoS One 12: e0173058, 2017.

19. Meng XY, Zhang HX, Mezei M and Cui M: Molecular docking: A powerful approach for structure-based drug discovery. Curr Comput Aided Drug Des 7: 146-157, 2011.

20. Hu L, Zhu H, Li L, Huang J, Sun W, Liu J, Li H, Luo Z, Wang J, Xue Y, et al: $( \pm)$ Japonones A and B, two pairs of new enantiomers with anti-KSHV activities from Hypericum japonicum. Sci Rep 6: 27588, 2016.

21. Livak KJ and Schmittgen TD: Analysis of relative gene expression data using real-time quantitative PCR and the 2(-Delta Delta C(T)) method. Methods 25: 402-408, 2001.

22. Toni $\mathrm{T}$ and Stumpf MP: Simulation-based model selection for dynamical systems in systems and population biology. Bioinformatics 26: 104-110, 2010.

23. Capitanio S and Wozniak RW: Host cell factors necessary for influenza a infection: Meta-analysis of genome wide studies. Quant Biol: 14, 2012.

24. Uetani K, Hiroi M, Meguro T, Ogawa H, Kamisako T, Ohmori Y and Erzurum SC: Influenza A virus abrogates IFN-gamma response in respiratory epithelial cells by disruption of the Jak/Stat pathway. Eur J Immunol 38: 1559-1573, 2008.

25. Ågerstam H, Karlsson C, Hansen N, Sandén C, Askmyr M, von Palffy $S$, Högberg $C$, Rissler $M$, Wunderlich $M$, Juliusson G, et al: Antibodies targeting human IL1RAP (IL1R3) show therapeutic effects in xenograft models of acute myeloid leukemia. Proc Natl Acad Sci USA 112: 10786-10791, 2015.

26. Chan RW, Leung CY, Nicholls JM, Peiris JS and Chan MC: Proinflammatory cytokine response and viral replication in mouse bone marrow derived macrophages infected with influenza H1N1 and H5N1 viruses. PLoS One 7: e51057, 2012.

27. Saller R, Büechi S, Meyrat R and Schmidhauser C: Combined herbal preparation for topical treatment of Herpes labialis. Forsch Komplementarmed Klass Naturheilkd 8: 373-382, 2001. 
28. Amritpal S: Herbal drugs as therapeutic agents. CRC Press Inc., Boca Raton, FL, p31, 2014.

29. Hossler P, Mulukutla BC and Hu WS: Systems analysis of $\mathrm{N}$-glycan processing in mammalian cells. PLoS One 2: e713, 2007.

30. Elbein AD, Dorling PR, Vosbeck K and Horisberger M: Swainsonine prevents the processing of the oligosaccharide chains of influenza virus hemagglutinin. J Biol Chem 257: $1573-1576,1982$.

31. Wang L and Suzuki T: Dual functions for cytosolic alpha-mannosidase (Man2C1): Its down-regulation causes mitochondria-dependent apoptosis independently of its alpha-mannosidase activity. J Biol Chem 288: 11887-11896, 2013.

32. Qu L, Ju JY, Chen SL, Shi Y, Xiang ZG, Zhou YQ, Tian Y, Liu Y and Zhu LP: Inhibition of the alpha-mannosidase Man2c1 gene expression enhances adhesion of Jurkat cells. Cell Res 16: 622-631, 2006

33. Tantale K, Mueller F, Kozulic-Pirher A, Lesne A, Victor JM, Robert MC, Capozi S, Chouaib R, Bäcker V, Mateos-Langerak J, et al: A single-molecule view of transcription reveals convoys of RNA polymerases and multi-scale bursting. Nat Commun 7: 12248, 2016.

34. Tafforeau L, Chantier T, Pradezynski F, Pellet J, Mangeot PE, Vidalain PO, Andre P, Rabourdin-Combe C and Lotteau V: Generation and comprehensive analysis of an influenza virus polymerase cellular interaction network. J Virol 85: 13010-13018, 2011.

35. Wagner R, Liedtke S, Kretzschmar E, Geyer H, Geyer R and Klenk HD: Elongation of the N-glycans of fowl plague virus hemagglutinin expressed in Spodoptera frugiperda (Sf9) cells by coexpression of human beta 1,2-N-acetylglucosaminyltransferase I. Glycobiology 6: 165-175, 1996.

36. Kobayashi Y and Suzuki Y: Evidence for N-glycan shielding of antigenic sites during evolution of human influenza A virus hemagglutinin. J Virol 86: 3446-3451, 2012.

37. Lybrand TP: Ligand-protein docking and rational drug design. Curr Opin Struct Biol 5: 224-228, 1995.

38. van den Elsen JM, Kuntz DA and Rose DR: Structure of Golg alpha-mannosidase II: A target for inhibition of growth and metastasis of cancer cells. EMBO J 20: 3008-3017, 2001

39. Stanley P, Taniguchi N and Aebi M: Chapter 9: N-Glycans. In: Essentials of glycobiology. 3rd edition. Varki A, Cummings RD Esko JD, Stanley P, Hart GW, Aebi M, Darvill AG, Kinoshita T, Packer NH, Prestegard JH, et al (eds). Cold Spring Harbor Laboratory Press, Cold Spring Harbor, NY, pp99-111, 2015.

40. Ye MH, Bao H, Meng Y, Guan LL, Stothard P and Plastow G Comparative transcriptomic analysis of porcine peripheral blood reveals differentially expressed genes from the cytokine-cytokine receptor interaction pathway related to health status. Genome 60 : 1021-1028, 2017.
41. Dey R, Ji K, Liu Z and Chen L: A cytokine-cytokine interaction in the assembly of higher-order structure and activation of the interleukine-3: Receptor complex. PLoS One 4: e5188, 2009.

42. Lin X, Huang C, Shi J, Wang R, Sun X, Liu X, Zhao L and Jin M: Investigation of pathogenesis of $\mathrm{H} 1 \mathrm{~N} 1$ influenza virus and swine streptococcus suis Serotype 2 co-infection in pigs by microarray analysis. PLoS One 10: e0124086, 2015.

43. Shinya K, Gao Y, Cilloniz C, Suzuki Y, Fujie M, Deng G, Zhu Q, Fan S, Makino A, Muramoto Y, et al: Integrated clinical, pathologic, virologic, and transcriptomic analysis of $\mathrm{H} 5 \mathrm{~N} 1$ influenza virus-induced viral pneumonia in the rhesus macaque. J Virol 86: 6055-6066, 2012.

44. Brummer G, Acevedo DS, Hu Q, Portsche M, Fang WB, Yao M, Zinda B, Myers M, Alvarez N, Fields P, et al: Chemokine signaling facilitates early-stage breast cancer survival and invasion through fibroblast-dependent mechanisms. Mol Cancer Res 16: 296-308, 2018.

45. Betakova T, Kostrabova A, Lachova V and Turianova L: Cytokines induced during influenza virus infection. Curr Pharm Des 23: 2616-2622, 2017.

46. Pagadala NS, Syed K and Tuszynski J: Software for molecular docking: A review. Biophys Rev 9: 91-102, 2017.

47. McCauley JW and Mahy BW: Structure and function of the influenza virus genome. Biochem J 211: 281-294, 1983.

48. Noda T and Kawaoka Y: Packaging of influenza virus genome: Robustness of selection. Proc Natl Acad Sci USA 109: 8797-8798, 2012.

49. Hall E, Dekker Nitert M, Volkov P, Malmgren S, Mulder H, Bacos $\mathrm{K}$ and Ling $\mathrm{C}$ : The effects of high glucose exposure on global gene expression and DNA methylation in human pancreatic islets. Mol Cell Endocrinol 472: 57-67, 2018.

50. Deaton AM and Bird A: CpG islands and the regulation of transcription. Genes Dev 25: 1010-1022, 2011.

51. Li J,Zhou B, Li C, Chen Q, Wang Y, Li Z, Chen T, Yang C, Jiang Z, Zhong N, et al: Lariciresinol-4-O- $\beta$-D-glucopyranoside from the root of Isatis indigotica inhibits influenza A virus-induced pro-inflammatory response. J Ethnopharmacol 174: 379-386, 2015.

52. Kang EH, Kown TY, Oh GT, Park WF, Park SI, Park SK and Lee YI: The flavonoid ellagic acid from a medicinal herb inhibits host immune tolerance induced by the hepatitis B virus-e antigen. Antiviral Res 72: 100-106, 2006.

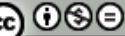

This work is licensed under a Creative Commons Attribution-NonCommercial-NoDerivatives 4.0 International (CC BY-NC-ND 4.0) License. 